Med Princ Pract 2011;20:491-492

DOI: $\underline{10.1159 / 000328427}$

\section{Hepatitis B Infection in Dentistry Setting Needs More Attention}

Seyed-Moayed Alavian ${ }^{\mathrm{a}}$,Nima Mahboobi ${ }^{\mathrm{b}, \mathrm{c}}$

a Baqiyatallah University of Medical Sciences, Research Center for Gastroenterology and Liver Disease, ${ }^{\mathrm{b}}$ Department of Oral and Maxillofacial Surgery, Faculty of Dentistry, Tehran University of Medical Sciences, and 'Students' Scientific Research Center, Tehran University of Medical Sciences, Tehran, Iran

We read with interest the published article entitled 'Occupational risks and hepatitis B vaccination status of dental auxiliaries in Nigeria' [1] in your esteemed journal. The study was well-designed, brief and easy to read. However, some aspects were speculative.

At the beginning of the third millennium, hepatitis B virus (HBV) remains a major global public health problem. More than a third of people have been infected worldwide, and of these, 350400 million are chronically infected [2]. In a study on the global challenge of $\mathrm{HBV}$, the dental community had the highest risk of infection amongst all health care personnel. Based on Cottone's study [3], dentists and oral surgeons were in the first rank, nurses, dental hygienists and assistants were in the third rank, and dental students and dental laboratory technicians were in the sixth and seventh ranks, respectively [3]. A previous survey [4] in the prevaccination era showed that HBV infection of dentists was approximately 3-6 times greater than that of the general population. Nonetheless, despite extensive vaccination programs against HBV since 1989, this infection has not yet been fully eradicated, and still is a major concern in dental fields [4]. Most dentists experience a needlestick or needle puncture of a finger at least once a week, mostly during recapping syringes and cleaning of instruments. Transmission of blood-borne pathogens following an exposure depends on the concentration of the virus in the blood or body fluid, the volume of infective material inoculated, the loss of infectivity during transfer of the inoculated material and the port of entry. The annual cumulative HBV infection risk of routine treatment of patients whose seropositivity is undisclosed is nearly 60 times greater than of human immunodeficiency virus (HIV) and mortality risk of $\mathrm{HBV}$ infection is 1.7 times greater than of HIV. Hence, greater attempt to restrict HBV exposure is required [4].
Based on the study of Azodo et al. [1], it is disappointing to find that almost half of the subjects did not receive $\mathrm{HBV}$ vaccine. Up to date, the most effective way to prevent HBV infection is vaccination. Nonetheless, since not all the recipients showed immune system response [5], it would be important to know the immune system response of the studied population.

In addition, we strongly recommend a vast and emergency vaccination program for Nigerian dental health care workers. Collaboration of the Ministry of Health and restricting the number of unvaccinated dental workers can facilitate the process. Nongovernmental organization assistance founding by international organizations appears mandatory for controlling the problem in developing countries. It should be pointed out that health care workers are labeled as a critical population; not only to be infected with the viruses during treatments, but also to transmit them during dental procedures [6]. Additionally, HBV can persist in dental plaster casts for more than 1 week. Hence, it is considered a great risk; especially for dental auxiliaries.

In another part of the assessment, a large rate of respondents mentioned that it was easier to be infected with HIV than HBV [1]. We think this finding shows that the population suffers from an incorrect belief.

Infection control courses monitored by the country's Minister of Health are recommended. It would also be useful if responses to awareness questions were presented. For a better assessment, further studies investigating postexposure management program of Nigerian dental auxiliaries and before-and-after educational program are recommended.

It is unfortunate to see that in a country with a high incidence of HIV, more than $25 \%$ of the participants mentioned they would not assist dentists treating an HIV-positive patient [1]. This negative attitude towards blood-borne pathogens still remains as documented in a previously published paper by Alavian et al. [6] who indicated that 16 of 50 dental clinics in Iran did not admit HBVinfected patients. Another 16 admitted them as the last resort of day and regretfully 32 clinics did not treat such patients at all. Fortunately, the younger generation of dentists is willing to treat HIV-infected patients [4].

Apparently, a global vaccination program seems the only available effective method for eliminating HBV outbreaks in dental offices. Policy makers in developing countries and in countries with financial problems should realize that health care workers and the dental community are groups with the highest risk of infection and transmission. Therefore, the program of vaccination should be applied to this populace first.

\section{KARGER}

Fax +41 613061234

E-Mail karger@karger.ch

www.karger.com (c) 2011 S. Karger AG, Basel

1011-7571/11/0205-0491\$38.00/0

Accessible online at:

www.karger.com/mpp 


\section{References}

1 Azodo CC, Ehigiator O, Ojo MA: Occupational risks and hepatitis B vaccination status of dental auxiliaries in Nigeria. Med Princ Pract 2010;19:364-366.

2 Te HS, Jensen DM: Epidemiology of hepatitis B and C viruses: a global overview. Clin Liver Dis 2010;14:1-21.

3 Cottone JA: The global challenge of hepatitis B: implications for dentistry. Int Dent J 1991;41:131-141.

-4 Mahboobi N, Agha-Hosseini F, Mahboobi N, Safari S, Lavanchy D, Alavian SM: Hepatitis B virus infection in dentistry: a forgotten topic. J Viral Hepat 2010;17:307-316.

5 Alavian SM, Mahboobi N, Mahboobi N: Anti-HBs antibody status and some of its associated factors in dental health care workers in Tehran University of Medical Sciences. Hepat Mon 2011;11:99-102.

6 Alavian SM, Moosavi SH, Mousavi SH, Azizi B, Akbari H: Study of admission rate of hepatitis $B$ surface antigen positive patients in 50 dentistry centers in Tehran. Hepat Mon 2008;8:67-69.

Nima Mahboobi

Department of Oral and Maxillofacial Surgery

Faculty of Dentistry, Tehran University of Medical Sciences

PO Box 14155/6537, Tehran (Iran)

Tel. +98911 144 7552, E-Mail nima.mahboobi@gmail.com

\section{Editor's Note}

Azodo et al., the authors of 'Occupational risks and hepatitis $B$ vaccination status of dental auxiliaries in Nigeria', were invited to reply to this letter, but they did not respond to the journal's invitation. 